\title{
A influência de Youtubers no processo de decisão dos espectadores: uma análise no segmento de beleza, games e ideologia
}

\section{Bruna Seibert Motta, Maíra Bittencourt e Pablo Moreno Fernandes Viana}

\section{Resumo}

Esse artigo propõe-se a analisar a influência que os chamados Youtubers exercem sobre a vida cotidiana e sobre as práticas de consumo de quem assiste seus conteúdos. 0 trabalho ancora-se na análise de três vídeos de "gurus" da beleza, gamers e conteúdo ideológico, observando como se constroem esses sujeitos da rede. 0 retorno por parte dos usuários foi verificado por meio de análise dos comentários deixados logo abaixo de cada vídeo. Dentre esses, foram criadas categorias para classificação dos conteúdos abordados pelos usuários, bem como o retorno obtido por parte do Youtuber.

\section{Palavras-Chave}

Youtube. Internautas. Influência no processo de decisão. Vídeos.

Bruna Seibert Motta | bmotta@usp.br Mestranda em Ciências da Comunicação pela Universidade de São Paulo - USP.

Maíra Bittencourt I maira_bittencourt@hotmail.com Doutoranda em Ciências da Comunicação pela Universidade de São Paulo - USP. Professora da FIAM-FAAM, São Paulo.

\section{Pablo Moreno Fernandes Viana}

I pablomoreno@gmail.com

Doutorando em Ciências da Comunicação pela Universidade de São Paulo - USP. Professor da PUC Minas.

\section{Introdução}

0 advento da internet possibilitou a experimentação de um novo comunicar, estabelecendo outra relação do sujeito com a informação. Neste cenário, a comunicação de massa deixou de existir apenas unilateralmente através dos meios tradicionais e passou a também circular em um ambiente no qual os indivíduos são capazes de selecionar conteúdos e partilhar ideias.

0 ambiente virtual que se organiza a partir da internet, como coloca Lévy (1996), não se opõe ao real, complementa-0. Passamos a ter nos espaços virtuais uma extensão da existência cotidiana, principalmente a partir da organização de redes sociais.

Mesmo ainda não sendo majoritária ${ }^{1}$, a comunicação propiciada pela internet é uma possibilidade que permite formas diferentes de comunicação. É a partir dessa perspectiva que se vislumbra o mote da mudança, mesmo que assimétrica, na formação da notícia, na publicidade e na maneira de informar da sociedade. 
Não se trata de tecnologias completamente novas e processos diferenciados por um todo. Nesse aspecto, concorda-se com Felinto (2011), que salienta a necessidade de perceber que, muitas vezes, pesquisadores entusiasmam-se com a cibercultura e chegam a afirmar que "as narrativas tecnológicas contemporâneas fundam-se numa retórica da ruptura radical com o passado e da novidade absoluta" (FELINTO, 2011, p. 43). Entretanto, há de se considerar que a web permitiu uma inovação jamais concedida por outro meio de comunicação: nela, os indivíduos possuem o diferenciado poder de publicar conteúdos.

Apareceu a internet, a máquina de inovação que, entre tantas outras coisas, também publica. Muito, tudo e de todo mundo. Nem todo mundo, claro, tem alguma coisa relevante a dizer para todo o resto do mundo, no sentido da indústria jornalística. [...] mas todo mundo tem alguma coisa a dizer para algum público, nem que seja sua família e amigos. (MEIRA, 2011)

Esse viés de publicação, aliado às alternativas das comunidades virtuais são fatores que dão suporte ao diálogo midiático e caracterizam as novas mídias, dotadas da possibilidade da circulação da informação, sendo o "tecido conjuntivo" (SHIRKY, 2011, p. 52) da sociedade. A mídia hoje é o que une as diversas pontas da sociedade: 0 cidadão ao
Estado, à cultura, à religião e tudo mais que fizer parte do invólucro de cada indivíduo.

A possibilidade que indivíduos interconectem-se através da rede permite que 0 usuário adentre espaços antes inacessíveis. Admite que ele possa dar sua opinião de forma mais ativa, sem necessitar que alguém ou algo aprove sua participação, como acontecia nos meios tradicionais de comunicação, dotados de equipes responsáveis por filtrar os conteúdos (gatekeepers) a serem veiculados. Ferramentas surgiram a partir dessa possibilidade, mas podemos citar o blog como um dos primeiros grandes fenômenos de publicação não mediada²

0 ambiente virtual evoluiu para outros formatos, criando novas possibilidades de publicação não só em texto, mas em áudio e vídeo inclusive. Enquanto na lógica dos meios de comunicação de massa infraestrutura tecnológica, repertório técnico e recursos humanos eram necessários para produzir conteúdo de mídia, na web o sujeito pode tornar-se produtor de conteúdo, veiculando mensagens sem custos e sem a necessidade de domínio de técnicas de produção, dispensando recursos tecnológicos complexos.

A partir disso, as organizações passam a enxergar estes ambientes como alternativa República. Secretaria de Comunicação Social. Pesquisa brasileira de mídia 2014 : hábitos de consumo de mídia pela população brasileira. - Brasília : Secom, 2014).

Tendo em vista que, apesar da publicação não ser mediada, a postagem pode estar inserida em um contexto institucionalizado e passível de regras predispostas. 
viável para divulgar seus negócios. Mais do que isso, o conteúdo gerado pelo sujeito anônimo endossa o produto ou serviço a ser publicizado da mesma forma que ocorreria com o marketing boca a boca, antes propagado apenas entre os pares e agora ampliado em nível global (MOTTA, B. S.; BATISTA, L., 2013, p. 41). Sernovitz (2012) reforça este argumento afirmando que a publicidade tradicional está em declínio, e a opinião do usuário ganha gradativa relevância, ao passo que se trata de "gente como a gente" difundindo sua opinião, espontaneamente ou não. À medida que a tecnologia se populariza e que as pessoas familiarizam-se com esse modelo de acesso às informações, mídias convencionais percebem-se obrigadas a promover alterações que dizem respeito aos desafios impostos pelas inovações, a fim de acompanhar as transformações do mercado.

Cidadãos com acesso à rede podem disponibilizar online aquilo que consideram pertinente, e essas publicações podem ser acessadas por poucos, mas com potencial de circulação que permite alcançar grande volume de acessos. "A modernidade libertou o homem das tradições que eram divinamente estabelecidas. 0 homem passou a ser soberano" (HALL, 1998, p. 23).

Evidente que muitos destes conteúdos possuem pouco grau de reflexão e não têm relevância noticiosa. Mesmo assim, a rede inova abrindo espaços para o não hegemônico. "A arquitetura unidirecional dos fluxos de informação dos mass media é alterada para uma arquitetura distribuída, com conexões multidirecionais entre todos nós, formando um ambiente de elevada interatividade e de múltiplos informantes interconectados" (AMADEU, 2008, p. 32). Isso não significa que as questões referentes à massificação foram superadas. Longe disso, 0 que é preciso perceber é que o mundo deu passos visando a um novo rumo, antes não possível (ou dificilmente alcançável), e que nesse novo espaço há coexistência de grandes corporações de mídia e de sujeitos anônimos.

A lógica que se instaura obedece aos princípios do rizoma (DELEUZE e GUATTARI, 1995), em uma estrutura descentralizada, que se organiza a partir de conexões, com mais ou menos força conforme o número de pontos interligados, sem forma e direção predefinidas, sem fórmulas de construção de conteúdo, surpreendendo, em alguns casos, grandes conglomerados de mídia com celebridades que emergem na rede.

Assim, é aceitável que haja decisões de quando os conteúdos serão consumidos, como um vídeo, um filme ou seriado, e ainda qual será a forma, 0 tempo e o local, como no Youtube, por exemplo, que revolucionou o modo de consumo de conteúdo audiovisual na internet.

A expansão do uso não apenas do YouTube, mas de alternativas futuras pode definir também a formação de novas camadas da sociedade, espectadores de frivolidades e do banco de dados permanente da web e de pessoas que não apenas informam-se de muitas fontes, mas 
que também assumem o papel de provocadora de discussão ao registrar online a sua opinião. (PASE, 2008, p. 250)

0 slogan do Youtube "Broadcast Yourself" reflete como ele instiga o sujeito a produzir conteúdo e tornar-se um ponto de transmissão na rede. Fundada em 2005, a plataforma disponibiliza conteúdos audiovisuais diversificados. 0 termo broadcasting está associado à lógica dos meios de comunicação de massa e à sua forma de transmissão de conteúdos a partir de uma origem para vários receptores. Quando o Youtube apropria-se desse termo e acrescenta a ele 0 yourself (si mesmo) em seu slogan, cria a ideia de que o próprio sujeito torna-se um canal de difusão para incontáveis receptores.

A relevância social do Youtube na contemporaneidade justifica-se por meio dos dados de acesso e conteúdo. Segundo estatísticas disponíveis no próprio site ${ }^{4}$, mais de um bilhão de usuários únicos visitam o Youtube todos os meses, e mais de seis bilhões de horas são assistidas a cada mês nos diversos canais disponíveis.

0 Youtube viabilizou com que 0 internauta se tornasse canal de comunicação, postando vídeos, permitindo a ele ser formador de opinião e agregando sujeitos em torno de discussões de temas diversificados. Esses produtores são chamados de Youtubers e concentram milhões de internautas em seus canais, por meio de assinaturas. 0 Youtuber posta vídeos de acordo com a frequência que lhe convém, e seu conteúdo pode ser assistido por qualquer internauta que encontre seus vídeos através de pesquisa, hiperlink ou pela assinatura de seu canal ${ }^{5}$.

Os assinantes dos canais dos Youtubers agrupam-se por interesse no conteúdo ou graças à sensação (ou desejo) de pertencimento (WOODWARD, 2000, p.8) e interagem por meio de avaliações ("gostei" ou "não gostei"), comentários e respostas. Essa agregação dos sujeitos em grupos de interesse comprova a ideia de que os Youtubers podem ser considerados líderes de opinião, em função do volume de pessoas que recebem suas mensagens e da discursividade que se estabelece em seus vídeos.

Neste artigo, o estudo está focado na abrangência conquistada através do Youtube. Serão analisados ícones da internet - pessoas anônimas que conquistaram fama e prestígio por meio do Youtube - e que hoje participam da vida social de milhares de sujeitos. Buscamos perceber que tipo

Em livre tradução ao português: "transmita-se".

www.youtube.com - Seção estatística. Acesso em novembro de 2014.

0 recurso assinar permite que um internauta receba notificações em sua caixa de e-mail toda vez que um novo conteúdo for disponibilizado pelo Youtuber em seu canal. 
de influência os Youtubers promovem no cotidiano e nas práticas de consumo de seus seguidores, a partir da interação proposta por meio dos comentários nos vídeos postados.

0 foco do trabalho está nos vídeos dos segmentos de beleza, games e com cunho ideológico - que abordam temáticas como política, economia e assuntos que perpassam o tecido social, tendo sido selecionado para a análise um representante de cada um dos segmentos indicados.

0 método a ser aplicado é 0 experimento laboratorial controlado que, de acordo com Sternberg (2000), considera amostras em um tempo e lugar específicos, as quais possam ser comparadas entre si. No caso, utilizaremos três amostras para averiguar a influência do meio nas respostas. Essas amostras serão organizadas a partir da observação não participante dos comentários disponíveis nos ambientes online de nosso interesse, que serão apresentados a seguir.

Acreditamos que a pesquisa pode ilustrar um estudo indicativo das oportunidades de divulgação de marcas e ideologias através desta plataforma, a qual já pode ser considerada um dos principais veículos de comunicação mundial, só faltando para tanto a democratização do acesso à rede.

\section{Situando a análise do objeto pelos efeitos psicológicos}

Em Psicologia Cognitiva, Sternberg (2000)

define a diferença entre atenção e consciência. A primeira é referente a toda informação que uma pessoa está manipulando, que envolve memória e sensações e na qual só é possível acessar uma determinada quantidade de informações por vez. Visa focalizar os recursos mentais - limitados sobre os processos cognitivos que nos são mais manifestos em dado momento. E é esta explicação que acreditamos que terá grande influência no resultado da presente pesquisa: o fato de que a amostra estará sugestionada pelo ambiente (contexto) a querer compartilhar da mesma opinião do expert ${ }^{6}$, induzidos pelo que o Youtuber usa, expõe e endossa.

Sobre a consciência, o autor afirma que sua abrangência é mais restrita por informações manipuláveis conscientemente. Logo, o público que interage com um vídeo por meio dos comentários no Youtube tende a utilizar-se de informações contextuais, presentes nos ambientes aos quais estarão expostos.

De certa forma, o significado de prime segue a mesma ideia da associação, mas de uma maneira mais direta e inconsciente. 0 prime, ainda segundo Sternberg, é quando algum estímulo nos 
remete a uma atitude, pensamento ou resposta. Grosso modo, ele nos permite fazer uma rota mental que nos induz a uma ação/resposta.

Mandel e Johnson (2002), entretanto, afirmam que pessoas com alto conhecimento sobre determinado assunto não são facilmente influenciáveis por prime devido à segurança que estes têm sobre suas respostas. Elas não necessitam de estímulos além do seu conhecimento para garantir respostas assertivas, ao contrário dos inexperientes/novatos que, a partir do medo de declarar algo errôneo e passível de críticas, optam pela segurança do estímulo oferecido (consciente ou inconscientemente). Sernovitz (2012) ressalta igualmente esta questão ao sustentar que os indivíduos relutam em demonstrar ignorância, aumentando a importância da opinião dos pares e valorizando sua tese de que o marketing boca a boca já sobrepõe-se à publicidade de massa.

A fim de demonstrar a ligação entre as influências do meio e as escolhas do consumidor, vamos observar as respostas em vídeos de três Youtubers distintos: um vídeo de Bruna Santina (Niina Secrets ${ }^{7}$ ) sobre maquiagens e dicas de beleza; outro de Cauê Moura (Desce a Letra ${ }^{8}$ ) sobre games; e um do Pirulla (Canal do Pirula ${ }^{9}$ ) sobre doação de medula óssea: um vídeo sobre notícias, outro sobre produtos e um ideológico.

\subsection{Entre os Youtubers e os internautas: o processo de penetração das informações na vida social}

Ao longo dos anos, os estudos acerca das teorias da comunicação acompanharam as transformações da sociedade. Particularmente, a partir da última década do século 21, a internet acelerou essas modificações ao propor uma nova lógica, na qual a relação hierárquica nos processos comunicativos foi transformada, abandonando a centralidade dos meios de comunicação de massa, permitindo que cada sujeito pudesse tornar-se potencialmente um polo emissor.

A configuração de uma sociedade em rede (CASTELLS, 2004), com poder de produção e emissão, promoveu amplo debate acerca dos papéis dos meios de comunicação, suscitando discussões de tom apocalíptico sobre o fim dos meios de comunicação de massa, entre outras coisas. Passada essa euforia, observase que ela foi apropriada socialmente e que as mídias tradicionais passaram a coexistir com ela, atualizando suas formas de comunicar, aproveitando-se dos seus recursos tecnológicos.

https://www.youtube.com/user/NiinaSecrets

https://www.youtube.com/user/descealetra 
As próprias teorias da comunicação atualizaramse para atender às discussões científicas sobre objetos da contemporaneidade. Diante desse raciocínio, pode-se aplicar à internet a teoria dos líderes de opinião, ou modelo dos dois estágios ${ }^{10}$, para a compreensão do objeto de estudo aqui proposto. Este modelo teórico foi concebido em 1948 a fim de estudar a influência dos meios de comunicação de massa sobre 0 comportamento de voto da sociedade.

0 modelo avançava na proposta de que a influência pelos meios de comunicação não era direta, alcançando, primeiramente, um líder de opinião, que disseminava a mensagem ao restante do seu grupo. Martino (2009) afirma que:

As influências transmitidas pelos meios possivelmente atinjam primeiro os líderes de opinião. Ou seja, indivíduos que repassam as informações dos meios a outros indivíduos do grupo, menos ativos, exercendo assim influência sobre estes. De onde seu nome: "comunicação em dois estágios". Com isso, o modelo fazia aparecer as redes de indivíduos que se servem de meios de comunicação, não indivíduos isolados e à mercê dos meios. (MARTINO, 2009, p. 2)

A grande contribuição deste modelo foi distanciarse da visão que sustentava a centralidade dos meios de comunicação, principalmente por deixar de lado a hipótese de manipulação absoluta por parte da mídia. A teoria passa a considerar as redes de relacionamento e também as trocas simbólicas que se estabelecem por meio das relações sociais. Tais trocas envolviam a experiência dos sujeitos com a mídia, no caso os líderes de opinião.

A sociedade experimentou um desenvolvimento muito rápido dos meios de comunicação no século 20 , principalmente a partir do advento da internet. 0 fenômeno batizado de web 2.0 (PRIM0, 2007) é um marco na ampliação da participação do sujeito na rede como um produtor de conteúdo. A partir daí surgem os blogs, as plataformas colaborativas e 0 Youtube, um dos símbolos dessa segunda geração de serviços online.

Ao observarmos os Youtubers, é possível analisálos sob o prisma do modelo teórico dos líderes de opinião. Seus vídeos abordam conteúdos diversificados, mas, em geral, focam na discussão sobre acontecimentos de relevância midiática. Por essa razão, os Youtubers podem ser considerados líderes de opinião para o público que os assiste.

0 líder de opinião difunde as mensagens (digamos, uma função propagação), mas ao fazerem isto não podem deixar de exercer uma função de selecionar aquelas que julgam pertinentes (função filtro), além disso, também podem, e frequentemente o fazem, "editam", recortam, comentam, avaliam e, portanto, transformam estas mensagens. (MARTINO, 2009, p. 3)

0 Youtuber é um sujeito anônimo, no sentido de que não tem presença midiática nos meios de comunicação de massa, que se apropria de 
informações da mídia e as repassa para um grupo de sujeitos conectados a ele por meio do Youtube, de acordo com critérios de relevância estabelecidos no perfil de seu canal. Ele produz vídeos, geralmente gravados com webcam, sem edição complexa (em comparação aos programas televisivos, por exemplo), sem uma ampla equipe de produção, como se observa nos meios de comunicação de massa. Nesses vídeos, ele geralmente fala para a câmera, em primeiro plano, comentando sobre os temas da pauta de seu canal.

Em comparação com o modelo teórico de 1948, a lógica torna-se um pouco diferente, ao passo que a comunicação no caso dos Youtubers dá-se em dois níveis midiáticos. No modelo original dos dois estágios de comunicação, as informações eram oferecidas dos meios de comunicação para um líder de opinião e este repassava às pessoas de seu grupo por meio da comunicação interpessoal. A lógica dos Youtubers diferenciase porque, primeiramente, o Youtuber consome algum conteúdo da mídia e, segundo os critérios de filtragem do seu canal, determina que tal conteúdo é relevante para ser comentado. Em seguida, produz o vídeo, edita-o e posta no Youtube. 0 internauta consome as notícias sob o ponto de vista do Youtuber, com uma dupla presença da mídia: a dos meios de comunicação e a do líder de opinião por meio da internet. Apesar disso, o Youtuber apresenta-se como sujeito anônimo, pelo fato de não ser celebridade das mídias tradicionais, o que lhe proporciona certa legitimidade perante os assinantes de seu canal (é uma pessoa anônima falando para outros anônimos). Por essa razão, é reconhecido como líder, tornando-se, com o passar do tempo, uma celebridade midiática da internet.

\section{Análise dos vídeos}

\section{1 "Videogame é coisa séria", de Cauê Moura}

0 vídeo "Videogame é coisa séria", disponibilizado no canal do Youtuber Cauê Moura, publicado em 19 de setembro de 2013, tem oito minutos de duração e discute como principal assunto o jogo Grand Theft Auto V (GTA V) ${ }^{11}$, lançado no Brasil naquela data. A descrição do vídeo no canal não traz muitas informações sobre 0 conteúdo e somente convida 0 internauta a 'favoritar' ou curtir o vídeo e a curtir e acompanhar o canal em outras redes sociais.

0 Youtuber começa o vídeo afirmando que será breve naquela edição por ter outros compromissos e mostra a capa do jogo e um controle de videogame, indicando qual é o motivo de sua pressa: jogar. Um fato curioso é que, apesar da afirmação, 0 vídeo em questão possui duração superior à média dos vídeos do canal (seis minutos). Cauê Moura explica por que 0

Jogo de videogame no qual o personagem principal precisa realizar tarefas que são disponibilizadas conforme a evolução da narrativa e dizem respeito a atividades que envolvem violência, drogas, roubos e diversos outros crimes. Seu nome reflete a uma das principais atividades do jogo: o roubo de automóveis. 
jogo é um tema importante, direcionando sua argumentação para aqueles que têm preconceito contra videogames. 0 argumento constrói-se em torno da quantidade de dinheiro envolvida na produção do GTA V e na comparação dos custos de produção do jogo com outros produtos de entretenimento. Ele compara os videogames com o cinema, abordando o faturamento de grandes produções e 0 faturamento de GTA. Ele aborda 0 preço do GTA V nos Estados Unidos e no Brasil para avaliar o potencial de arrecadação do jogo em função de seu custo, do público consumidor e sinaliza que o jogo deve superar, e muito, seus custos de produção. Ele informa que somente na data de lançamento o GTA $V$ faturou US\$ $800.000 .000,00$ e faz a conversão do valor para reais e explica que até hoje 0 filme Titanic não arrecadou essa quantia.

Na segunda questão discutida, Cauê Moura pede que seja exibida somente metade da vinheta de transição, pois o próximo conteúdo ainda teria relação com o GTA $V$. Ele relata um caso registrado nos EUA de três homens que se passaram por policiais para comprar o jogo sem precisar enfrentar na fila, mas que foram detidos e podem ficar até um ano na cadeia pela infração.

Aos três minutos e vinte e cinco segundos, 0 Youtuber muda de tema e passa a comentar sobre outros conteúdos, como o caso de um agricultor assassinado com um tiro de escopeta, disparado acidentalmente por seu cachorro. A outra notícia é sobre um possível atirador que teria invadido a
Casa Branca, mas que, na verdade, era um homem soltando bombinhas no local.

Após apresentar as notícias, aos $07 \min 15 \mathrm{~s}$, ele mostra novamente 0 controle do videogame, afirmando que irá encerrar a transmissão para ir ao seu compromisso. A vinheta de encerramento é exibida e, antes de finalizar, o Youtuber convida 0 espectador a assistir ao vídeo postado na semana anterior e destaca as pautas da edição.

0 total de exibições do vídeo até 0 dia 15 de novembro de 2013 era de 808.239. No que diz respeito às manifestações dos internautas em "gostei" e "não gostei", 96.562 sujeitos gostaram do vídeo, ao passo que 720 não gostaram. Do total de pessoas que assistiram ao vídeo, esse número corresponde a 12\% de participação nesse formato, sendo que a grande maioria optou pela opção "gostei".

Com relação à participação por meio de comentários, 0 vídeo possui até a data de análise 6.491 comentários. Em comparação com 0 total de visualizações, esse número de comentários corresponde a um total de $0,8 \%$ de discussão. Para a análise, os comentários deste e dos demais vídeos foram organizados sob o critério de "mais recentes primeiro", de modo que se pudesse observar a discussão promovida pelo conteúdo, mesmo algum tempo após a sua postagem.

0 comentário mais recente postado datava de 15/11/2013, e tinha a autoria do usuário 
Insainous. Ele era uma repetição do

antepenúltimo comentário, do usuário João

Escobar, também postado em 15/11/2013. 0s dois comentários traziam uma manifestação contra a rede social Google + e não tinham relação com 0 conteúdo do vídeo. 0 último comentário analisado datava de "duas semanas atrás"12, em relação à data da análise.

Observando-se os 50 primeiros comentários exibidos pelo critério selecionado, nota-se, no que se refere ao tópico principal, que 28 deles estão

relacionados com videogames em geral, enquanto 22 têm relação especificamente ao GTA $V$.

Os comentários promovem pouca discussão, sendo a maioria deles frases soltas elogiando 0 jogo ou o Youtuber. Sete comentários elogiam a introdução que o Youtuber faz do vídeo, defendendo a importância do videogame em função da quantia que movimenta. Três comentários são respostas a comentários

Figura 1: Comentários do vídeo.

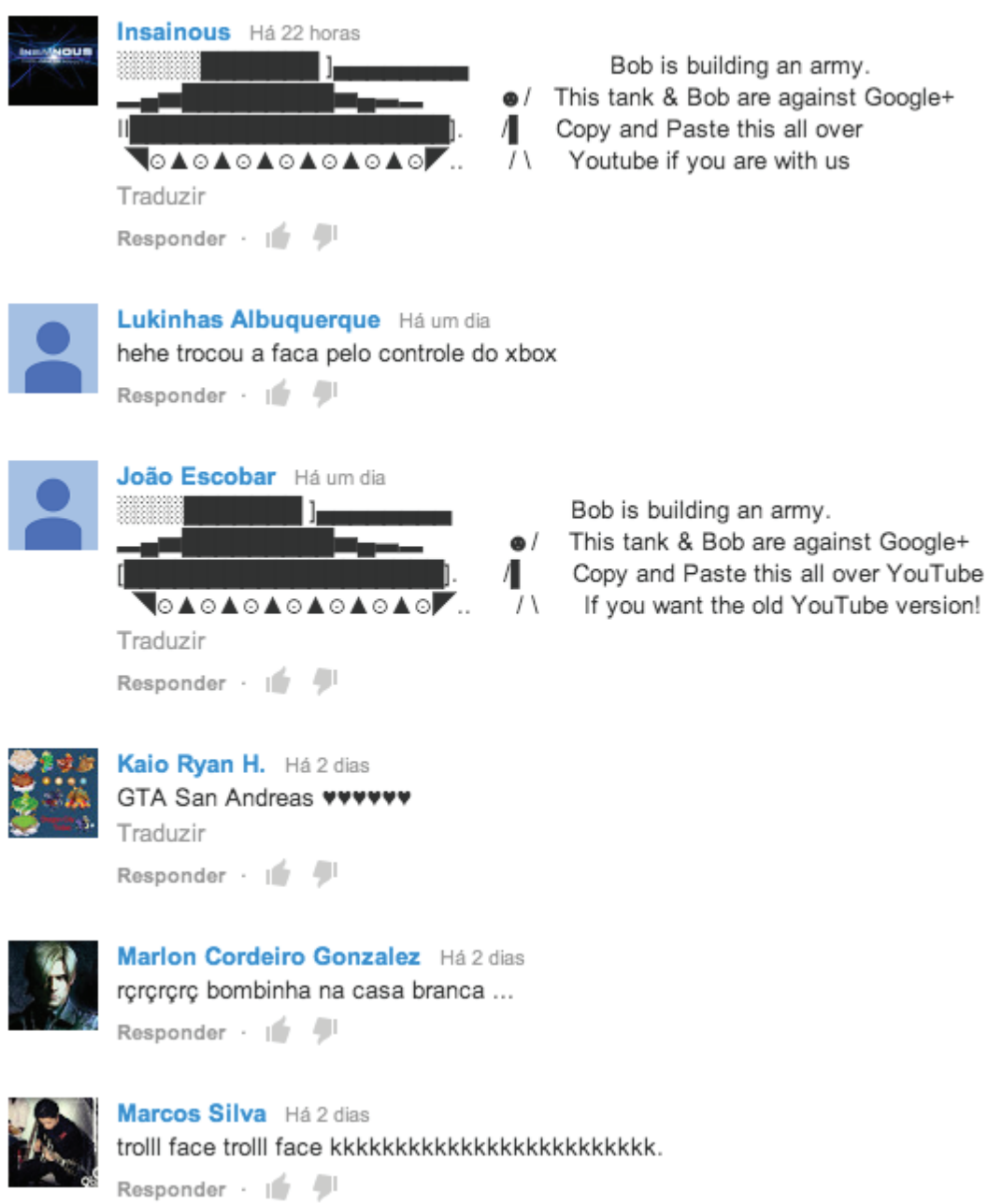




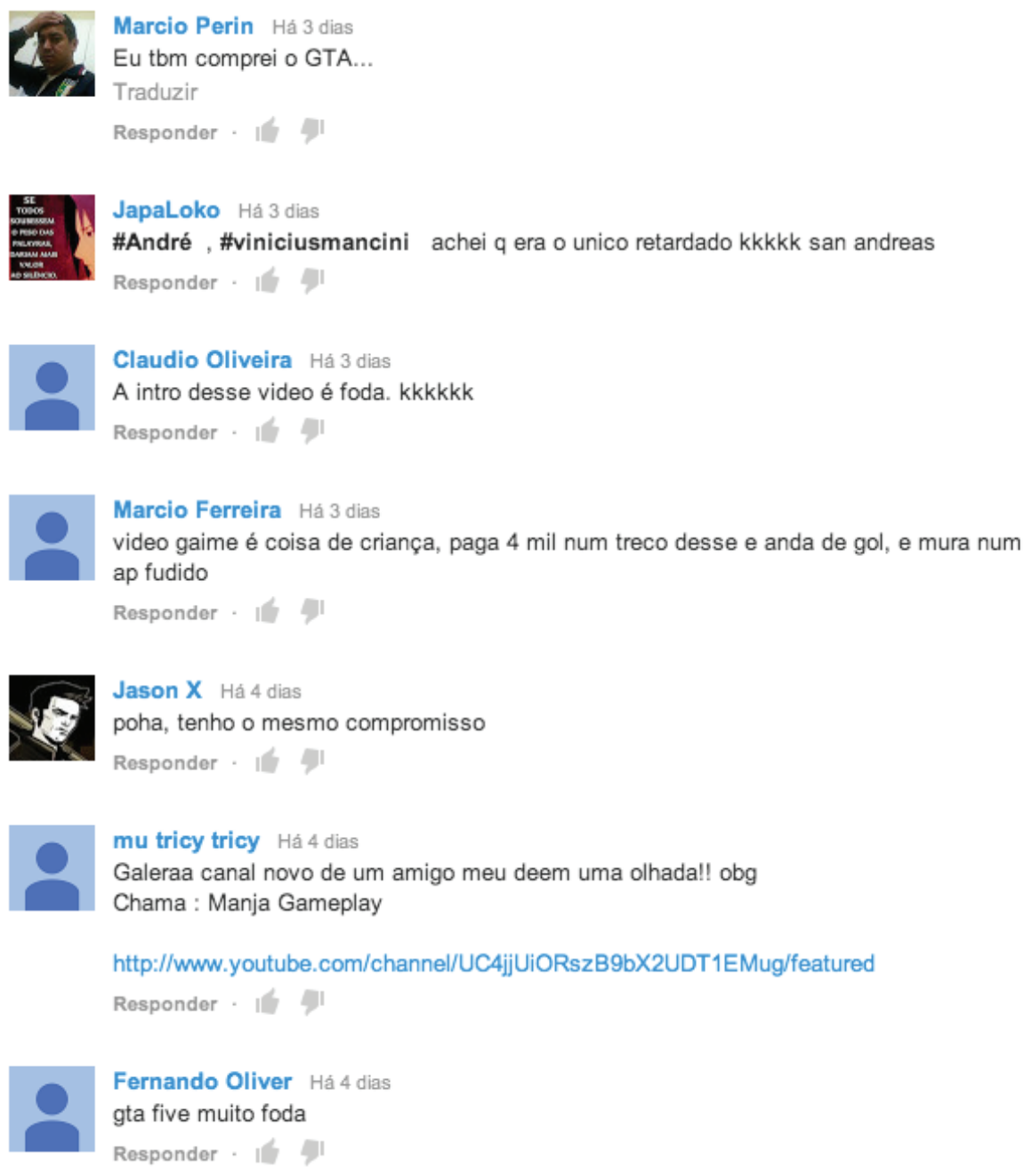

Fonte: www.youtube.com

postados, aproveitando o recurso "responder" do Youtube, uma ferramenta que visa incentivar a discussão nos tópicos. No entanto, pouca coisa é debatida. Dessas respostas, duas são ao comentário do usuário "Spadaxim meiaperna", que pergunta "PQ SÓ EU NÃO TENHO O GTA V?". Outra resposta é a um comentário fazendo propaganda de um vídeo de outro usuário, sem relação com 0 assunto discutido no canal.
Além deste, outros dois comentários convidam os internautas a assistirem a vídeos de outros canais, um deles mais explicitamente, outro de forma mais discreta.

Observando-se a influência do Youtuber sobre os consumidores do conteúdo oferecido, constatase que a maior discussão nos comentários ocorre em torno do tema principal do vídeo. A 
Figura 3: Comentários referentes ao valor do jogo e sua relevância no mercado financeiro

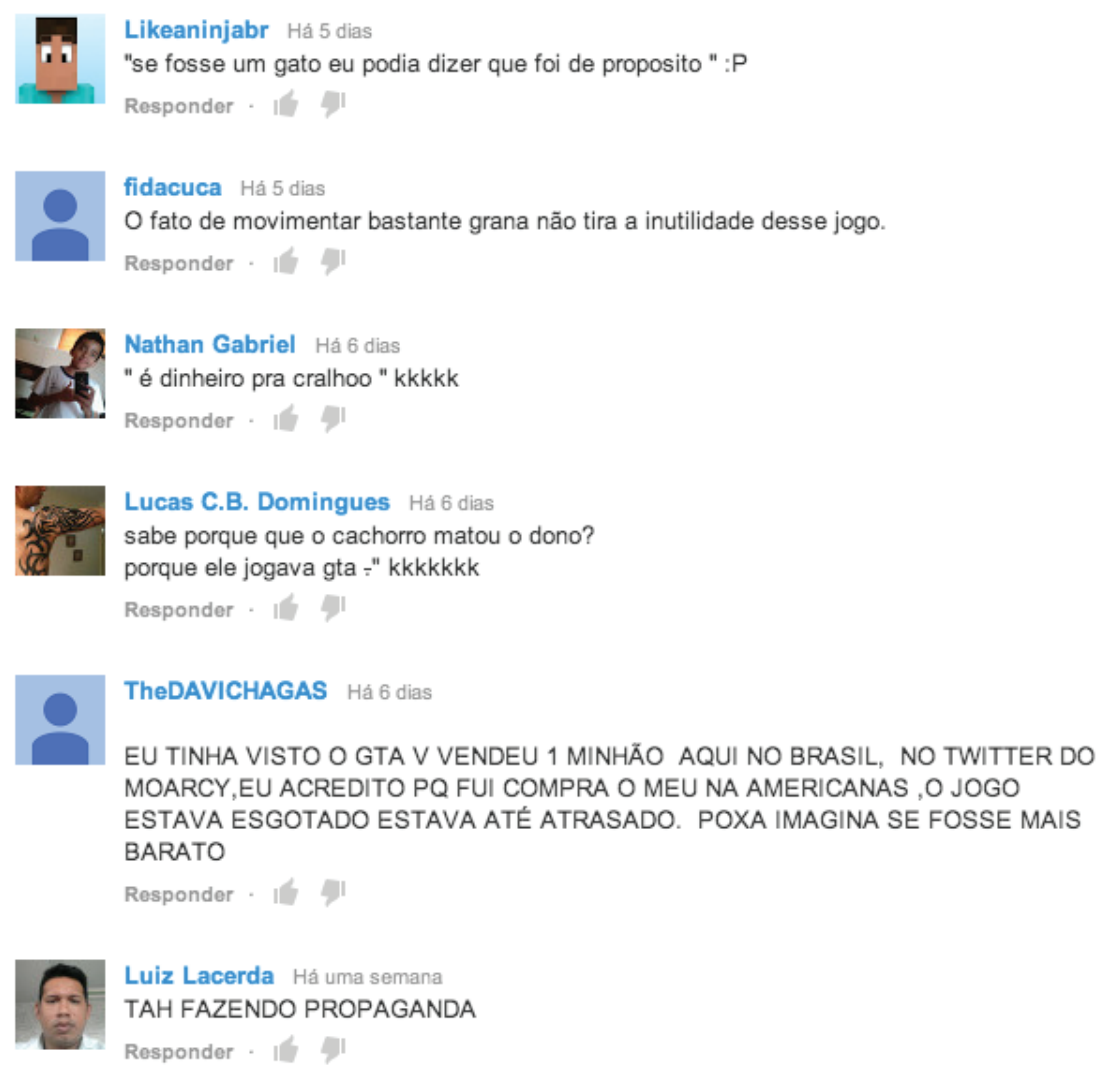

Fonte: www.youtube.com

maior participação nos comentários se dá em manifestações positivas sobre a introdução do vídeo, principalmente pelo raciocínio construído em torno da importância social do videogame na sociedade. Percebe-se que 0 argumento apresentado pelo Youtuber é considerado válido pela maioria dos internautas que participam, que devem concordar com a afirmação e veem no raciocínio apresentado uma forma de justificar seu interesse pelos videogames em outras discussões. Somente um comentário manifesta-se contrário, criticando o argumento, alegando que rodeios também movimentam grande quantidade de dinheiro, mas que isso não é suficiente para justificar a crueldade com animais nesse tipo de evento. Outra manifestação contrária ocorre por meio do comentário de um sujeito que alega que o Youtuber está fazendo propaganda do jogo. No entanto, não há, entre os selecionados, outros comentários que endossam tal opinião. Por essa razão, a discussão sobre a espontaneidade do tema não ganha força na amostra.

\subsection{Maquiagem para valorizar o sorriso, de Niina Secrets}

0 vídeo "Maquiagem para valorizar o sorriso!", disponibilizado pelo canal do Youtube Niina 
Secrets, é patrocinado abertamente pelo gel dental Diamond Atraction da CloseUp. 0 canal da Youtuber traz dicas de maquiagens, penteados, produtos e viagens, normalmente sem patrocínio de marcas. Neste vídeo particularmente, ela fala os dados técnicos do produto em questão e faz o tutorial de uma maquiagem para realçar 0 sorriso de dentes brancos, dando dicas e sugerindo produtos.

Os comentários estão divididos basicamente em 4 macrocategorias: a) comentários sobre a maquiagem em si; b) comentários sobre 0 creme dental; c) elogios à Niina Secrets; d) comentários recriminando as comentaristas que fazem críticas.

0 total de exibições do vídeo até 0 dia 17 de novembro de 2013 era de 50.960, o que é bastante inferior à maioria dos vídeos do canal, possivelmente por tratar-se de um vídeo patrocinado. A respeito dos "gostei" e "não gostei", dois mil setecentos e onze (2711) sujeitos gostaram do vídeo, ao passo que cento e cinquenta e sete (157) não gostaram. Apenas 5,62\% das pessoas que assistiram ao vídeo opinaram através do "gostei" ou "não gostei", sendo que a maioria optou pelo "gostei".

Figura 4: CloseUp interagindo nos comentários

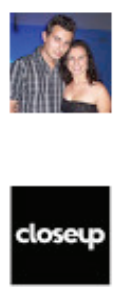

Yanie S Há uma semana (editada)

Apaixonada pelo batom =))

Responder

CloseupBrasil Há uma semana

Oi Kátia Costa! Que bom, ficamos muito felizes em saber sobre isso. Conte sempre

conosco;)

Responder

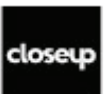

CloseupBrasil Há uma semana

Millena Paiva, tudo bem com você? Depois que experimentar nos conte o que achou,

combinado? Até!

Responder
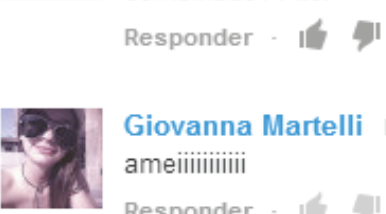

Giovanna Martelli Há uma semana

ameiiiiiiiiiii

Responder

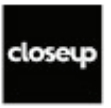

CloseupBrasil Há uma semana (editada)

E ai Júlia Barnes, beleza? Sim, temos Close Up Diamond Attaction na embalagem de cor

azul, rosa e verde. Se você quiser mais detalhes pode nos procurar, ok? Ficaremos

felizes em ajudar. Até mais!

Responder

CloseupBrasil Há uma semana

Camila Sabino, se quiser, pode entrar em contato com a gente para conversarmos um pouco mais, o que acha? Só nos procurar na nossa fan page no Facebook. Valeu, até mais!

Responder 
A respeito da participação através de comentários, 0 vídeo possui até a data supracitada trezentos e vinte e um (321) comentários. Em comparação com o total de visualizações, esse número de comentários corresponde a um total de $0,62 \%$ de discussão.

A partir da observação dos 50 primeiros comentários, identificamos 16 comentários elogiando a Youtuber, 12 elogiando a maquiagem, cinco defendendo a Niina de comentários negativos/críticas e sete falando sobre a pasta de dente, sendo cinco destes publicados pela própria CloseUp, conforme indicado na Figura 4.

A Figura 5 mostra os elogios e 0 apoio, mesmo que curto e simples, ao trabalho da Youtuber.

Entretanto, também é possível observar, em meio aos comentários, que as críticas estão presentes e que estas são tratadas com impaciência pelas fãs de Niina, como vemos na Figura 6.

Figura 5: Elogios à Youtuber e à maquiagem

Maria De Fatima Souza Há 2 dias

A m e i **

Traduzir

Responder

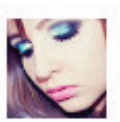

Dri Lamour Há 3 dias

qual o batom nina?

Responder

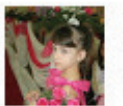

Gaby mendonça Há 4 dias

linda

Traduzir

Responder

Beatriz Cristina Há 4 dias

Adorei a Maquiagem!...Niina,faz a Make da Avril Lavigne do Clip - Let Me Go.

Responder

Emily Santos Há 5 dias

Você é muito linda Niina! A make ficou perfeita.

Responder

Alexia Laila Há 6 dias

achei otmo mais ela errou na hora de colocar os cilios portissos mais te amo ninna!!!

Responder 
Telma de araujo dias Há uma semana

assiste ai pessoal e dá uma orça pra divulgar, novo funk

Mc Thiaguinho PH - Além de 100 \$.J 2013 (( Lado Sul Produções ))

Responder

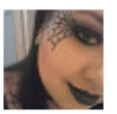

Francyeli Almeida Há uma semana

Niina maquiagem PERFEITA ! não liga pras recalcadas, gente que so gosta de deixar os

outros pra baixo não merecem que dão ouvidos pra elas... vc é linda beijos!

Responder

Celly Casteli Há uma semana

Ficouuu linda como sempre s2

Responder

Fonte: www.youtube.com

Podem-se observar alguns comentários

afirmando a busca pelo produto apresentado

pela Youtuber. Contudo, os comentários

elogiando a Niina e sua maquiagem se

sobressaíram. Há certa resistência observada

à inserção de publicidade em vídeos de

Youtubers, que foi possível perceber graças à

baixa quantidade de visualizações deste vídeo

(em relação às demais postagens do canal),

0 que nos leva a pensar que as pessoas que 0

assistiram são mais engajadas com a Youtuber,

comprovado pelo fato de a maioria dos

comentários ser referente à própria Niina.

\subsection{Tempo, Pirula e Medula, do Pirulla 25}

0 terceiro vídeo analisado é intitulado "Tempo,

Pirula e Medula", do canal do Youtuber Pirulla25.

Conforme descrição própria, o canal é voltado à

ciência, religião, evolução e comédia. No dia 20

de novembro de 2013, possuía 117.604 inscritos

e 5.668.487 visualizações, desde seu início, em

12 de julho de 2006. De modo geral, os vídeos do

canal tratam de assuntos do cotidiano, carregados

com informações de pesquisas realizadas, aliadas

à opinião pessoal. Nesse vídeo específico, 0

Youtuber aborda a temática da doação de medula 
óssea para portadores de leucemia. 0 tema veio à tona por causa de uma amiga do Youtuber que está lutando contra a doença.

0 vídeo foi visualizado por 133.882 usuários, curtido por 15.463 e comentado por 3.146 pessoas desde a data de postagem, em 24 de julho de 2013, até 0 dia 20 de novembro de 2013. 0 material tem duração de 26 minutos e 36 segundos.

Nele, o Youtuber começa conversando com seus telespectadores sobre sua possível ausência nos próximos meses e, com 1 minuto e 51 segundos, entra na questão da doença leucemia. Ele começa narrando a situação de uma amiga que está passando pelo problema e logo entra em uma abordagem mais técnica sobre a leucemia, doação de medula e compatibilidade de doadores. Faz um apelo para que seus telespectadores se cadastrem como doadores e mostra imagens próprias no dia do seu cadastramento junto ao REDOME ${ }^{13}$. Ele encerra reforçando a importância de mais pessoas se cadastrarem e desmitifica o procedimento.

Na descrição, ele coloca diversos links para acesso direto aos centros de doações, bem como informações sobre endereço, telefones e websites em alguns estados brasileiros.

Nos comentários analisados, os 50 primeiros em ordem cronológica dos mais atuais para os menos atuais, percebe-se um posicionamento bastante claro do público. Se nos demais vídeos era possível visualizar uma grande maioria falando sobre questões diversas, aqui os comentários são bastante focados na temática do vídeo. Existem, obviamente, aqueles que comentam sobre as "piadas" feitas pelo Youtuber e ainda os que destoam do conteúdo, mas, em grande parte, estão fazendo referência ao foco exposto pelo Youtuber, como se pode ver nos dez comentários mais recentes exibidos na Figura 7.

Desses dez comentários, é possível fazer a seguinte divisão: cinco elogiam o conteúdo e frisam que mudaram seus pensamentos por causa das informações contidas no vídeo; dois colocam questionamentos sobre assuntos relacionados ao tema principal do audiovisual; e outros três abordam a piada feita pelo Youtuber durante 0 vídeo. Sendo assim, percebe-se que a maioria posicionou-se a favor do conteúdo e com mudança de atitude substancial por causa da abordagem. 0 primeiro comentário na Figura 7 explicita inclusive uma ação prática do usuário, que não ficou somente na web e que colocou em prática os "ensinamentos" adquiridos com o Youtuber.

Na sequência dos comentários, verifica-se outro tipo de intervenção. Um Youtuber comenta no vídeo que gostaria de ter publicado um vídeo em seu canal com resposta a esse em questão, mas que, por alguns motivos, não conseguiu, então 


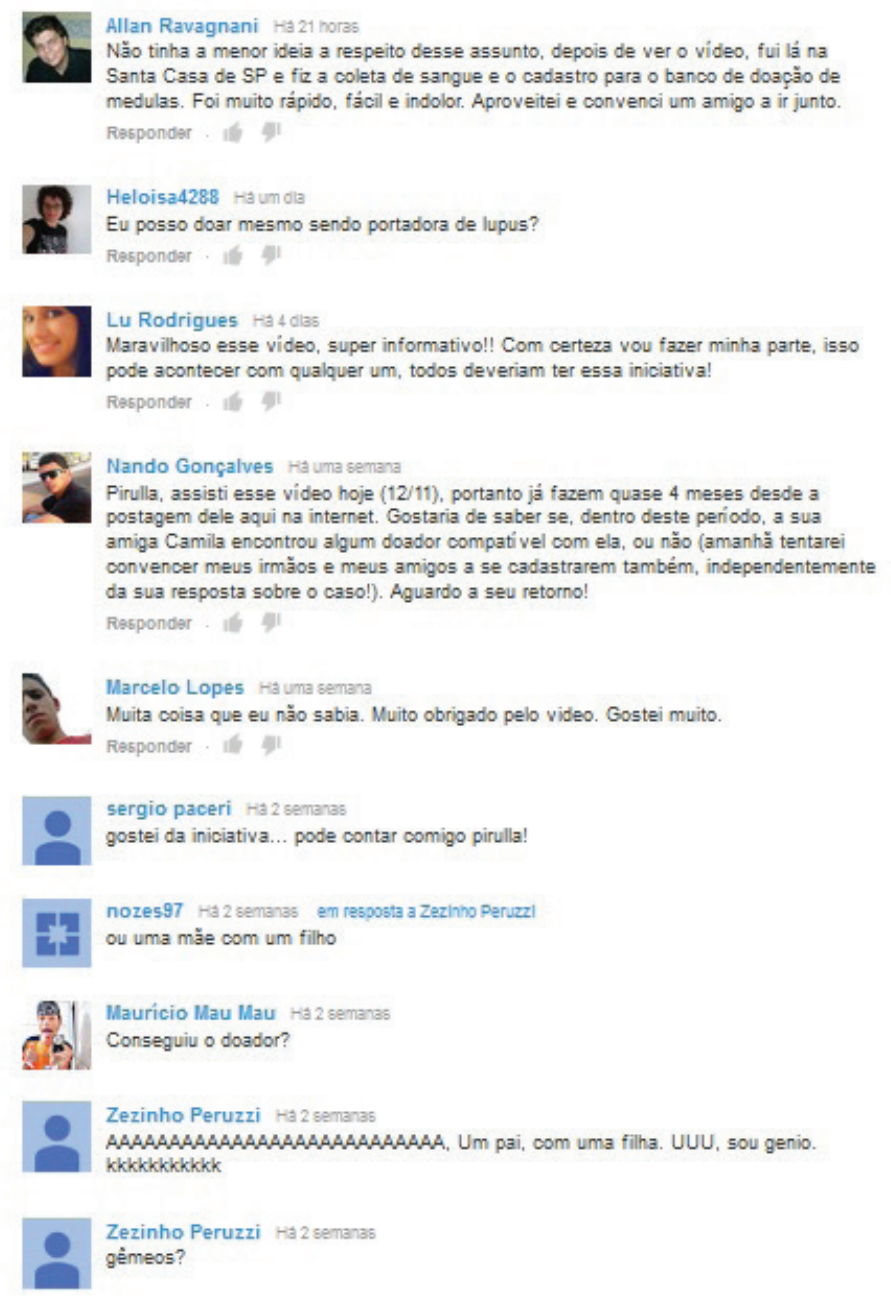

Fonte: www.youtube.com

daria seu feedback via comentário mesmo. 0 comentário pode ser visualizado na Figura 8.

Além de salientar detalhes sobre suas intenções de vídeo, ele, Ronan Peixoto, que possui um canal no segmento de games, deixa claro que o material postado pelo Pirulla foi de extrema importância para esclarecimentos sobre a doença e o processo de doação. Ele afirma ainda que já se cadastrou e está aguardando com muita expectativa um chamado para doação.
Percebe-se aqui, novamente, a mudança de atitude no real, a partir do assunto levantado no meio virtual, o que comprova o pensamento de Lévy (1996), de que o virtual é uma extensão de nossas atitudes no mundo real e vice-versa. Pode-se reconhecer também a clara influência do Youtuber na vida de quem 0 assiste.

Na imagem apresentada na Figura 9, constatam-se outros dois tipos de comentários. Um tipo seriam aqueles que respondem 
Figura 8: Comentários do Youtuber Ronan Peixoto

jean alesi Ha 3 semanas

como ser filho do meu irmào?

1.

Pirulla25 Ha 3 semanas em resposta a Fonan Petroto

Cara, eu te agradep̧o muito pelo seu depoimento! Valeu!

Ronan Peixoto Ha 3 semanas em resposta a Ronan Pelooto

Sinto até felicidade por estar simplesmente escrevendo aqui. Espero que sua amiga

seja salva, assim como outras pessoas. Seria imensurável pra mim, se eu fosse compativel com ela e pudesse salvá-la, mas como já se passaram 2 meses, năo devo ser Mas tomara com outra pessoa também. Um Abraco!

Ronan Peixoto Ha 3 semanas em resposta a Fonan Pelinoto

Obviamente, se eu tivesse pesquisado, talvez tivesse sanado as dúvidas, mas em um video, o aprendizado mais lúdico ajuda muito na conscientizaçăo. OU SEJA, graças ao seu video, eu aprendi o que era, e fui doar, fui ajudar nesta causa tăo nobre.
Continua...

Ronan Peixoto: Ha 3 semanas em resposta a Ronan Pelooto

Tinham amigos meu que realmente năo poderiam doar sangue, mas que năo sei se poderiam medula (hepatite e outras complicacóes), e năo sei o que fazer quanto à isso. Talvez eu fale pra eles irem assim mesmo, mas o problema é que năo acho que ele irăo, uma pena. Bom, era isso. Achei seu vídeo fantástico, e deixe eu adicionar o seguinte: Eu tinha dúvidas sobre doạ̧ăo de medula, eu năo entendia o que era. Continua.

Ronan Peixoto Ha 3 semanas em resposta a Fonan Petrota

Eu, na verdade, até me atrasei pra ir doar, só fui mesmo no dia 9 de setembro (mas, de novo, antes tarde do que nunca) Era pra eu ter conseguido doar sangue junto, mas năo pude, porque estava com suspeita de gripe (năo se concretizou, foi uma pena năo ter doado naquele dia, e ainda năo voltei, pois sempre estou com feridas) Eu fui com dois amigos que foi quem consegui reunir, por variados motivos. Continua...

Ronan Peixoto Ha 3 semanas em resposta a Fonan Pelloto

Depois desisti de fazer um vídeo, e fique só de te responder, e como vocé pode ver, me esqueci também. Estava vendo os vídeos seus e do Yuri sobre pesquisas com animais, e ele mencionou algo que me motivou a vir aqui agora: Feedback. Eu achei que já estava de bom tamanho apenas ter feito meu cadastro de medula óssea, mas me lembrei que vock (e todos os youtubers) querem o feedback dos inscritos. Bom, aqui estou eu pra te falar isso XD Continua.

Ronan Peixoto Ha 3 semanas

Olá Pirulla. Na verdade, eu estou atrasadissimo com essa resposta, mas antes tarde do que nunca. Vi seu vídeo, e fiquei de fazer um pequeno vídeo resposta, mostrando minha ida lá no Hemocentro aqui em Minas, onde moro, para ajudar na campanha. Infelizmente, por alguns contratempos e vacilos meus, eu năo consegui gravar (cheguei a gravar a parte inicial na porta da instituiçăo), entăo pensei em fazer o vídeo sem isso. Continua..

Fonte: www.youtube.com

aos questionamentos levantados por seus

pares, como no caso de Rafael Virno, que perguntou se poderia doar medula tendo 15 anos, e da resposta, que veio do usuário Alex Schrijnemaekers. 0 outro tipo de comentário presente nessa figura são aqueles que fazem referência a outros canais, como, por exemplo, a fala de Tamires Lima, que elogia o vídeo e diz que acessou após ter tido recomendação de outro Youtuber (Cauê Moura).
Na última imagem, observa-se que a influência não ocorre somente em pontos isolados ou em uma relação tradicional de comunicação, na qual o emissor envia a mensagem a um receptor e recebe um feedback. Percebe-se uma comunicação circular que transcorre entre os diversos membros envolvidos no processo. Uns influenciam os outros, com maior ou menor grau de complexidade. Os próprios usuários esclarecem questões e partilham conhecimentos entre si. Outros Youtubers também 
Figura 9: Comentários com interações entre si e com referência a outros canais

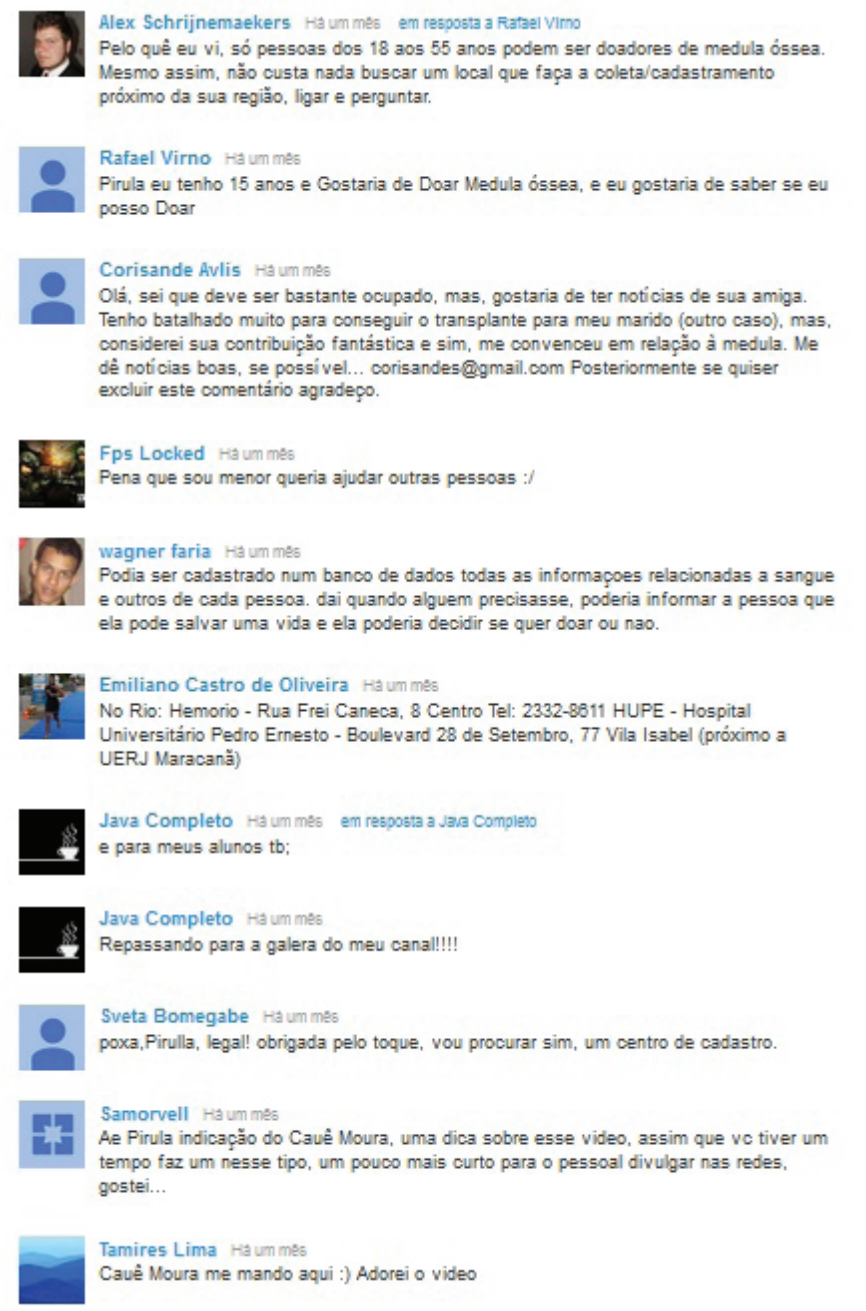

Fonte: www.youtube.com

interagem com os usuários e com os próprios agentes que estão postando os materiais, seja através de referências em seu próprio canal ou ainda de participação direta.

\section{Considerações Finais}

Partimos do pressuposto de que, quando nos concentramos para desenvolver alguma tarefa, nosso cérebro, automaticamente, inicia um processo de seleção de estímulos que serão úteis para a consecução do feito. Assim, tomamos fatores como 0 ambiente ou leituras anteriores - no caso do blog - como precedentes de acesso inconsciente à informação, isto é, ao pensarmos para responder a uma das perguntas, nosso cérebro rapidamente busca estímulos e informações que nos auxiliem na elaboração desta resposta.

Certamente, no caso exposto, são ativados os módulos mentais que tenham referência com 0 tema tratado, e esses módulos são mais ou menos 
fortalecidos conforme seu uso. Assim, alguém que habitualmente acessa canais dos Youtubers já possui conhecimento prévio sobre 0 tema e uma maior consistência de experiências, o que aumenta o potencial de influência.

Conforme discutido, nota-se que a informação apresentada influencia os usuários por meio da atenção. A informação apresentada é manipulada pelo Youtuber por meio de memórias e sensações, uma vez que a audiência dos canais estabelece com eles uma relação de interesse. 0 sujeito que consome o conteúdo disponível em qualquer um dos três canais chegou até lá através do sistema de busca do Youtube ou da ferramenta de assinatura do canal, acessando o conteúdo a partir da notificação de que 0 vídeo estava disponível, enviada aos assinantes. Assim, ao assistir à mensagem, 0 sujeito a acessa por meio da atenção. A amostra é sugestionada pelo ambiente e participa daquele conteúdo (seja por meio da assinatura do canal, do "gostei" ou dos comentários) por partilhar da mesma opinião que o Youtuber expõe.

No que se refere ao prime, constata-se, principalmente no segundo vídeo analisado, a resistência do público à inserção de conteúdo publicitário no vídeo da Youtuber. No primeiro vídeo, em alguns comentários, é sugerido que 0 Youtuber faz publicidade do jogo GTA $V$, mas essa argumentação não se endossa diante dos pares. Já no segundo vídeo, a publicidade do creme dental CloseUp é reconhecida pela audiência, que passa a discutir isso nos comentários. A lógica da rede nega as estruturas dos meios de comunicação tradicionais, e isso acontece também com as estratégias de publicidade. Dessa forma, veicular uma mensagem publicitária no conteúdo de um vídeo de Youtuber - do modo como se faz tradicionalmente na televisão - provoca estranhamento entre a imagem construída e a fala do expert, uma vez que o Youtuber constrói um público fiel para o seu canal por meio do reconhecimento desse status de anonimato. A inserção de publicidade, sem a exposição clara para o público de que se trata de uma mensagem com fins comerciais, afeta 0 potencial de influência da mensagem. No caso do terceiro vídeo, a maneira como a história é contada causa envolvimento pela espontaneidade do relato do Youtuber, embora não se possa afirmar ao certo que a iniciativa é 100\% espontânea.

Percebe-se que, nos casos analisados, houve esse processo de intervenção nas diversas formas da comunicação. Os Youtubers analisados possuem papel significativo na vida de seus espectadores, bem como os próprios usuários também exercem influência junto aos seus pares.

No presente estudo, a percepção da comunicação pode ser considerada de modo misto. A visão que ambos os públicos têm de cosméticos, games e ideologias é distinta, devido às formas como elas estão expostas, mas também de acordo com 0 aprendizado que elas já possuem sobre 0 assunto. Isso fica evidente quando consideramos os experts no tópico em questão, sujeitos que 
buscam informações em outras fontes também especializadas, conhecem e testam produtos e possuem atitudes favoráveis a determinadas marcas e ideais. A percepção das marcas/ ideais pode ser considerada uma combinação de experiência pessoal e comunicação sensorial momentânea do meio de informação.

Além disso, existem questões importantes sobre 0 contexto da comunicação que precisam ser levadas em consideração para a percepção na comunicação, afinal, quando o contexto de uma mensagem é favorável para uma determinada informação, os receptores tendem a avaliar de forma mais positiva o que está sendo transmitido. A partir daí, é possível entender a influência dos Youtubers, seja na divulgação de produtos nos quais as marcas aparecem de forma contextualizada com outros temas, de maneira informativa e não meramente propagandística, seja em novos ideais que podem construir argumentos a favor ou contra algo.

Há uma série de condições mediadoras e estimuladoras que atingem os órgãos sensoriais no momento da percepção que influenciarão, por sua vez, a recepção de determinada mensagem. Além disso, fatos que extrapolam a situação em si também influenciam a percepção e a recepção, consequentemente. São eles: a seletividade perceptiva, a experiência prévia e consequente disposição para responder e o condicionamento.

A presença de outros comentários semelhantes às ideias de quem assiste ao vídeo influencia a motivação de resposta. Por isso, examinamos como um sujeito comum torna-se formador de opinião, que interfere no comportamento dos espectadores, ou seja, até que ponto os receptores imitam ou gostariam de imitar os experts, comprando os produtos recomendados por eles ou moldando suas ideologias a partir de seus argumentos, declarando isso por meio dos comentários.

É sabido que, para trabalhar com a atenção do consumidor, há de se considerar todas as suas experiências precedentes, suas vivências e influências desde o primeiro estímulo até o contato com o produto. Assim, considerar aspectos que incitem a lembrança de fatores que podem direcionar sua atenção para determinado elemento do produto-objeto-ideia é fundamental quando se tem o objetivo de incutir neste consumidor informações sobre um produto, ideologia ou marca.

Pode-se concluir que 0 Youtube, bem como outros sites que trabalham com esse formato representam um suporte a um tipo de comunicação não experimentado nos veículos de comunicação tradicionais. Aqui, o processo da comunicação de massa deixa de existir no modelo clássico com emissor, meio, mensagem, receptor e feedback e passa a existir de modo circular em que não há somente um emissor, nem tão pouco um receptor massivo.

Quem recebe a mensagem também pode participar, seja em formato de vídeo (em respostas a 
conteúdos de outros canais), de comentário ou outros tipos de interação e assim também se exerce influência sobre outros usuários.

Apesar do potencial de participação, verificase que a maior parte dessas interações dáse por meio de comandos mais simples, os quais demandam menos esforço do sujeito. 0 clique em "gostei" é a maior das interações nos três vídeos analisados, embora esteja muito distante do volume de visualizações do conteúdo. A participação por meio das ferramentas de discursividade (comentários e vídeos de resposta) é muito pequena nos três casos, o que comprova que, apesar do potencial de interação e participação viabilizado pela rede, há pouco interesse na participação em conteúdos de terceiros.

Constatamos que os Youtubers são, sim, novos formadores de opinião, mas exercem ainda 0 papel de levantar temas para a reflexão pública a partir dos conteúdos veiculados na mídia. No primeiro vídeo analisado, verifica-se que o Youtuber promove a discussão a partir de notícias relevantes sobre determinados tópicos; a segunda aproveita-se da temática de seu canal para inserir uma mensagem publicitária de um produto que estava com uma campanha em veiculação na mídia no período; e o terceiro que se aproveita de um momento pessoal (segundo relatado) para trazer à discussão uma questão frequentemente trabalhada em campanhas de mobilização social e indica outros caminhos para os espectadores obterem mais informações sobre 0 assunto, a doação de medula. Assim, comprovase a perspectiva teórica de 1948, tendo esses sujeitos como líderes de opinião, em uma versão atualizada, na qual os dois níveis de comunicação dão-se a partir de esferas midiáticas.

Por fim, pode-se reconhecer que, apesar de a rede possibilitar a emergência de novos formadores de opinião, antes pessoas anônimas, os quais passam a ser líderes que agregam sujeitos em torno de seus canais pessoais, conclui-se que a transformação desse Youtuber em um líder está vinculada diretamente ao seu capital simbólico. Ele precisa, primeiramente, afirmar-se como expert naquele tópico para, em seguida, ao longo do tempo, ser reconhecido por pares (anônimos) como tal, para, com o tempo, tornar-se referência e seu conteúdo ganhar relevância (por meio de visualizações, assinantes e outras formas de participação) nas estruturas rizomáticas da rede, surgindo em resultados de busca.

\section{Referências}

AMADEU, Sérgio. Além das redes de colaboração: internet, diversidade cultural e tecnologias do poder. Salvador: EDUFBA, 2008.

CASTELLS, Manuel. A galáxia da internet: reflexões sobre internet, negócios e sociedade. Lisboa: Fundação Calouste Gulbenkian, 2004.

DELEUZE, Gilles; GUATTARI, Félix. Mil platôs: capitalismo e esquizofrenia. Rio de Janeiro: Ed. 34, 1995. 
FELINTO, E. Em Busca do Tempo Perdido.

0 Sequestro da História na Cibercultura e os Desafios da Teoria da Mídia. In search of lost time. The hijacking of history in cyberculture and the challenges of media theory. MATRIZes, São Paulo, 4, mai. 2011. Disponível em: http://www.matrizes.usp.br/ ojs/index.php/matrizes/article/view/138. Acesso em: 15 Nov. 2011.

HALL, Stuart. (1998). A identidade cultural na pósmodernidade. Rio de Janeiro: DP\& A.

MARTINO, Luiz C. Dois Estágios da Comunicação versus Efeitos Limitados: Uma releitura. IN: XVIII Encontro da Compós, na PUC-MG, Belo Horizonte, MG, junho de 2009. Disponível em: www.compos.org.br LÉVY, Pierre. 0 que é o virtual?. São Paulo: Ed. 34, 1996. 157p.

MEIRA, Sílvio. A nova indústria cultural. Disponível em: < http://smeira.blog.terra.com.br/>. Acesso em: 05 jun. 2011.

MENDEL, N. JOHNSON E.J. (2002) When Web pages influence choice: Effects of visual primes on experts and novices. Journal of consumer research, Vol. 29 Setember, PP. 235-245.

MOTTA, B. S.; BATISTA, L. A crença no desconhecido: como a prossumerização está mudando os hábitos de consumo. Cadernos de Comunicação (UFSM), v.17, p. 37-5-, 2013.

PASE, André. Vídeo online, alternativa para as mudanças da TV na cultura digital. Tese de doutorado apresentada ao programa de pós-graduação da Pontifícia Universidade Católica do Rio Grande do Sul. Porto Alegre, p. 250, 2008.

PRIM0, Alex. 0 aspecto relacional das interações na Web 2.0. E- Compós (Brasília), v. 9, p. 1-21, 2007.

SERNOVITZ, A. Marketing boca a boca. São Paulo:

Cultrix, 2012.
SHIRKY, C. A cultura da participação: Criatividade e generosidade no mundo conectado. Rio de Janeiro: Zahar, 2011.

STERNBERG, Robert J. Psicologia Cognitiva. Porto Alegre: Artes Médicas Sul, 2000.

WOODWARD, K. Identidade e diferença: uma introdução teórica e conceitual. In: SILVA, T. T. (Org.). Identidade e diferença: a perspectiva dos estudos culturais. Petrópolis: Vozes, 2000. p. 7-72. 
The influence of Youtubers in decision-making of audiences: an analysis in segment of beauty, games and ideology

La influencia de youtubers en la toma de decisiones de los espectadores: un análisis en el segmento de belleza, juegos y ideología

\section{Abstract}

This article analyzes the influence of Youtubers about everyday life and consumption practices in their audiences. The analysis is anchored in three videos about beauty, electronic games and ideological content made by these gurus, watching how their arguments influences the audience. The feedback from users has been verified through analysis of comments left below each video. Among these, categories for classification of content covered by the users were created as well as the return obtained by the Youtuber. and reception.

\section{Keywords}

Youtube. Netizen. Decision Making. Video.

\section{Resumen}

Este artículo trata de identificar las interacciones entre la televisión e Internet en el entorno de los medios de comunicación donde se inserta el Jornal Nacional, revisar las actuales características del lenguaje de narrativas audiovisuales periodísticas y entender cómo se establecen las relaciones con el público en la experiencia de la cultura participativa potenciada por la convergencia, a partir del análisis televisivo de la cobertura de las protestas de junio( en Brasil) de noticiero del más grande audiencia del país. Se basa en las contribuciones de las teorías de la comunicación y de los estudios de periodismo y recepción.

\section{Palabras-Clave}

Youtube. Cibernauta. Toma de decisiones. Video. 


\section{Expediente}

A revista E-Compós é a publicação científica em formato eletrônico da Associação Nacional dos Programas de Pós-Graduação em Comunicação (Compós). Lançada em 2004, tem como principal finalidade difundir a produção acadêmica de pesquisadores da área de Comunicação, inseridos em instituições do Brasil e do exterior.

\section{E-COMPÓS I www.e-compos.org.br I E-ISSN 1808-2599}

Revista da Associação Nacional dos Programas

de Pós-Graduação em Comunicacão.

Brasília, v.17, n.3, set./dez. 2014

A identificação das edições, a partir de 2008

passa a ser volume anual com três números.

\section{CONSELHO EDITORIAL}

Afonso Albuquerque, Universidade Federal Fluminense, Brasil Alberto Carlos Augusto Klein, Universidade Estadual de Londrina, Brasil Alex Fernando Teixeira Primo, Universidade Federal do Rio Grande do Sul, Brasil Rio Grande do Sul, Brasi

Ana Gruszynski, Universidade Federal do Rio Grande do Sul, Brasil Ana Silvia Lopes Davi Médola, Universidade Estadual Paulista, Brasil André Luiz Martins Lemos, Universidade Federal da Bahia, Brasi Ângela Freire Prysthon, Universidade Federal de Pernambuco, Brasil Antônio Fausto Neto, Universidade do Vale do Rio dos Sinos, Brasil Antonio Carlos Hohlfeldt, Pontifícia Universidade Católica do Rio Grande do Sul, Brasil Antonio Roberto Chiachiri Filho, Faculdade Cásper Líbero, Brasi Arlindo Ribeiro Machado, Universidade de São Paulo, Brasil Arthur Autran Franco de Sá Neto, Universidade Federal de São Carlos, Brasil Benjamim Picado, Universidade Federal Fluminense, Brasil César Geraldo Guimarães, Universidade Federal de Minas Gerais, Brasil Cristiane Freitas Gutfreind, Pontifícia Universidade Católica do Rio Grande do Sul, Brasil Denilson Lopes, Universidade Federal do Rio de Janeiro, Brasil Denize Correa Araujo, Universidade Tuiuti do Paraná, Brasil Edilson Cazeloto, Universidade Paulista, Brasil

Eduardo Vicente, Universidade de São Paulo, Brasil

Eneus Trindade, Universidade de São Paulo, Brasil

Erick Felinto de Oliveira, Universidade do Estado do Rio de Janeiro, Brasil Florence Dravet, Universidade Católica de Brasilia, Brasil

Gelson Santana, Universidade Anhembi/Morumbi, Brasi Gilson Vieira Monteiro, Universidade Federal do Amazonas, Brasil Gislene da Silva, Universidade Federal de Santa Catarina, Brasil Guillermo Orozco Gómez, Universidad de Guadalajara, México Gustavo Daudt Fischer, Universidade do Vale do Rio dos Sinos, Brasil Hector Ospina, Universidad de Manizales, Colômbia Herom Vargas, Universidade Municipal de São Caetano do Sul, Brasil leda Tucherman, Universidade Federal do Rio de Janeiro, Brasil Inês Vitorino, Universidade Federal do Ceará, Brasil Janice Caiafa, Universidade Federal do Rio de Janeiro, Brasil Jay David Bolter, Georgia Institute of Technology, Estados Unidos Jeder Silveira Janotti Junior, Universidade Federal de Pernambuco, Brasi João Freire Filho, Universidade Federal do Rio de Janeiro, Brasil John DH Downing, University of Texas at Austin, Estados Unidos Ana Carolina Damboriarena Escosteguy, Pontifícia Universidade Católica do

José Afonso da Silva Junior, Universidade Federal de Pernambuco, Brasil José Carlos Rodrigues, Pontifícia Universidade Católica do Rio de Janeiro, Brasil José Luiz Aidar Prado, Pontifícia Universidade Católica de São Paulo, Brasil José Luiz Warren Jardim Gomes Braga, Universidade do Vale do Rio dos Sinos, Brasil Juremir Machado da Silva, Pontifícia Universidade Católica do Rio Grande do Sul, Brasil Laan Mendes Barros, Universidade Metodista de São Paulo, Brasi Lance Strate, Fordham University, USA, Estados Unidos Lorraine Leu, University of Bristol, Grã-Bretanha Lucia Leão, Pontifícia Universidade Católica de São Paulo, Brasil Luciana Panke, Universidade Federal do Paraná, Brasil Luiz Claudio Martino, Universidade de Brasília, Brasil Malena Segura Contrera, Universidade Paulista, Brasil Márcio de Vasconcellos Serelle, Pontifícia Universidade Católica de Minas Gerais, Brasil Maria Aparecida Baccega, Universidade de São Paulo e Escola Superior de Propaganda e Marketing, Brasi Maria das Graças Pinto Coelho, Universidade Federal do Rio Grande do Norte, Brasil Maria Immacolata Vassallo de Lopes, Universidade de São Paulo, Brasil Maria Luiza Martins de Mendonça, Universidade Federal de Goiás, Brasil Mauro de Souza Ventura, Universidade Estadual Paulista, Brasil Mauro Pereira Porto, Tulane University, Estados Unidos Nilda Aparecida Jacks, Universidade Federal do Rio Grande do Sul, Brasil Paulo Roberto Gibaldi Vaz, Universidade Federal do Rio de Janeiro, Brasil Potiguara Mendes Silveira Jr, Universidade Federal de Juiz de Fora, Brasil Renato Cordeiro Gomes, Pontifícia Universidade Católica do Rio de Janeiro, Brasil Robert K Logan, University of Toronto, Canadá

Ronaldo George Helal, Universidade do Estado do Rio de Janeiro, Brasil Rosana de Lima Soares, Universidade de São Paulo, Brasi Rose Melo Rocha, Escola Superior de Propaganda e Marketing, Brasil Rossana Reguillo, Instituto de Estudos Superiores do Ocidente, México Rousiley Celi Moreira Maia, Universidade Federal de Minas Gerais, Brasi Sebastião Carlos de Morais Squirra, Universidade Metodista de São Paulo, Brasil Sebastião Guilherme Albano da Costa, Universidade Federal do Rio Grande do Norte, Brasil

Simone Maria Andrade Pereira de Sá, Universidade Federal Fluminense, Brasi Suzete Venturelli, Universidade de Brasília, Brasil

Tiago Quiroga Fausto Neto, Universidade de Brasília, Brasil

Valerio Fuenzalida Fernández, Puc-Chile, Chile

Veneza Mayora Ronsini, Universidade Federal de Santa Maria, Brasi Vera Regina Veiga França, Universidade Federal de Minas Gerais, Brasil

\section{COMISSÃO EDITORIAL}

Cristiane Freitas Gutfreind I Pontifícia Universidade Católica do Rio Grande do Sul, Brasil Irene Machado I Universidade de São Paulo, Brasil

Jorge Cardoso Filho I Universidade Federal do Recôncavo da Bahia, Brasil Universidade Federal da Bahia, Brasil

CONSULTORES AD HOC

Adriana Amaral, Universidade do Vale do Rio dos Sinos, Brasil

Alexandre Rocha da Silva, Universidade Federal do Rio Grande do Sul, Brasi

Arthur Ituassu, Pontifícia Universidade Católica do Rio de Janeiro, Brasil

Bruno Souza Leal, Universidade Federal de Minas Gerais, Brasil

Elizabeth Bastos Duarte, Universidade Federal de Santa Maria, Brasil

Francisco Paulo Jamil Marques, Universidade Federal do Ceará, Brasi

Maurício Lissovsky, Universidade Federal do Rio de Janeiro, Brasil

Suzana Kilpp, Universidade do Vale do Rio dos Sinos, Brasil

Vander Casaqui, Escola Superior de Propaganda e Marketing, Brasi

EDIÇ̃̃O DE TEXTO E RESUMOS I Press Revisão

SECRETÁRIA EXECUTIVA I Helena Stigger

EDITORAÇÃo ELETRÔNICA I Roka Estúdio
COMPÓS I www.compos.org.br

Associação Nacional dos Programas de Pós-Graduação em Comunicação

Presidente

Eduardo Morettin

Universidade de São Paulo, Brasil

eduardomorettin@usp.br

Vice-presidente

Inês Vitorino

Universidade Federal do Ceará, Brasil

ines@ufc.br

Secretária-Geral

Gislene da Silva

Universidade Federal de Santa Catarina, Brasil

gislenedasilva@gmail.com 